\title{
"Ei, juiz, vai tomar no cu": políticas torcedoras e do futebol e sonoridades de xingamentos em performances masculinas
}

\author{
"Hey, referee, stick it to your ass": \\ football and cheering politics and sonorities \\ of cursing in masculine performances
}

\author{
Pedro Silva Marra \\ Universidade Federal do Espírito Santo (UFES), Vitória / Brasil \\ Doutor em Comunicação Social, UFF \\ pedromarra@gmail.com
}

\begin{abstract}
RESUMo: Este artigo discute as formas como as sonoridades de xingamentos utilizados por torcedores de futebol em gritos e cantos nas arquibancadas constituem performances masculinas que confirmam seu caráter heteronormativo, conferem a tais palavras uma ambiguidade jocosa, ou as reterritorializam em uma ofensividade de outra ordem. Nestas disputas de gênero, as materialidades sonoras fundamentam a compreensão dos momentos em que um palavrão tensiona, reproduz ou desloca estruturas sociais patriarcais no âmbito do esporte. 0 artigo ainda aponta a necessidade de mais estudos acerca das relações corruptas que se dão no interior da gestão do futebol e entre dirigentes e certos grupos de torcedores, ora exibidas, ora escamoteadas por tais performances de gênero.
\end{abstract}

Palavras-chave: Futebol; Performances masculinas; Sonoridades; Torcida; Xingamentos.

ABSTRACT: This paper discusses how sonorities of cursing accessed by football fans in screams and chants on the terraces constitute masculine performances which confirm their heteronormative character, grant to those words a jocular ambiguity, or reterritorialize them in an offense of another order. In those gender disputes, the sonic materialities underlie the understanding of the moments in which swearing strains, reproduces or displaces patriarchal social structures in football. The paper also elicits the need for more studies on the corrupt relations that take place in football administration among sports managers and organized groups of fans, which are sometimes displayed or retracted by those gender performances.

KEYwoRDS: Football; Masculine performances; Sonorities; Fans; Cursing. 


\section{回}

Áudio 1, Galoucura: "Ei, juiz, vai tomar no cu!"1

Vozes guturais, timbres rasgados e ritmos agressivos são sonoridades constantemente acionadas por torcedores de futebol para evocar afetividades tão distintas como amor pelo time, indignação com uma marcação equivocada ou erro de atleta em campo, jocosidade com o amigo adversário, ou ódio ao oponente, por exemplo. Nestas ocasiões, as arquibancadas entoam - em uníssonos que tomam todo o estádio, ou a partir de grupos organizados e de localização territorial bem definida - canções, gritos, palavras de ordem e outros sons baseados em repertórios simbólicos que trabalham distinções heteronormativas entre homem e mulher, heterossexual e homossexual; atividade, submissão e passividade; valentia, apatia e covardia. Se o futebol é campo fértil para a formação e reprodução de sensibilidades masculinas nas sociedades contemporâneas, este artigo investiga os aspectos audíveis que compõem performances de gênero nesta prática.

A partir de gravações sonoras realizadas em trabalho de campo em partidas do Clube Atlético Mineiro, mais conhecido como Galo, entre os anos de 2011 e 2015, analisamos como tais repertórios são manipulados em seus parâmetros acústicos de intensidade, frequência e espacialidade a fim de realizar ações como indignar-se, odiar brincar ou amar. Neste jogo entre a semântica de termos chulos e as sonoridades com que são empregadas, os torcedores põem a prova a masculinidade dos adversários, dos árbitros, instituições, além de sua própria. Assim, de maneira tênue, confirmam o caráter preconceituoso de xingamentos; conferem a tais palavras uma ambiguidade jocosa; ou as reterritorializam em uma ofensividade de outra ordem, voltada contra injustiças cometidas dentro ou fora de campo. Estas dinâmicas se conectam às disputas em torno de recursos materiais e

\footnotetext{
1 Importante: para ouvir o áudio é necessário baixar este PDF para o computador, recomendamos o uso do Adobe Reader ou Foxit.
} 
simbólicos que viabilizam a prática esportiva, bem como de formas de expressar o apoio à equipe pela sua torcida.

Este artigo trabalha o som como afeto a fim de compreendê-lo como agência torcedora que conforma os corpos de membros da torcida e de atletas a partir da mobilização e modulação de músicas e sons. Se assumirmos que as sonoridades se apresentam como sinal de movimento comunicado no espaço, vibração de um corpo que ressoa em outro, percebe-se como se configuram como uma mediação que conforma uma "entrada acústica para campos afetivos", ${ }^{2}$ mais do que um veículo para os sentimentos. Nestas dinâmicas um som não necessariamente significa, mas faz, permite agências, realiza ações, coloniza espaços, inclusive o dos corpos. $^{3}$ Assim, está sempre ligado a dinâmicas de violência, entendida aqui não como agressividade física ou simbólica, mas como a ocupação ou bloqueio de espaço por agentes, contra a resistência de outros sujeitos, o que a coloca no cerne da disputa esportiva. ${ }^{4}$ Esta perspectiva, traz também a possibilidade de percebê-la como algo positivo, sobretudo para pensar as formas de luta dos sujeitos contra injustiças sofridas.

No processo, o trabalho busca elementos que permitam tatear uma pragmática sonora que estabelece diferenciações de gênero e fronteiras porosas entre campos de ação, o que delineia interfaces e adjacências entre identidades de gênero que flutuam de acordo com situações, relações entre os interlocutores e as formas sônicas com que são trabalhadas. Percebe-se, portanto, uma partilha do sensível, que distribui a legitimidade de certas práticas torcedoras enquanto nega a existência de outras, além de ora exibir, ora escamotear as relações corruptas que se dão no interior da gestão do futebol e entre dirigentes e certos grupos de torcedores. Neste contexto, a ação política é aquela que fratura tal distribuição e desorganiza sua institucionalidade, ao expor suas contradições e delinear novos sujeitos que, ao contrário daquilo que está estabelecido, afirmam-se dotados de

\footnotetext{
2 THOMPSON; BIDDLE. Sound, music, affect, p. 16.

${ }^{3}$ DAUGHTRY. Thanatosonics, p. 33.

${ }^{4}$ GUMBRECHT. Is there anything wrong with violence, p. 69.
} 
voz e que por isso requerem o seu quinhão nos espaços de debate e decisão, no caso do futebol a arquibancada. ${ }^{5}$

\section{Pragmáticas do PAlaVRão e do XINGAMENTo}

Palavrões são termos que remetem a escatologia, de conotação sexual, ou relacionados a grupos marginalizados, o que lhes confere um caráter de interdição e tabu. Xingar é a ação de ofender verbalmente, muitas vezes lançando mão de palavrões, mas nem sempre. Assim, a passagem do palavrão ao xingar não é automática, da mesma forma que ao xingar nem sempre se intenciona ofender. 0 palavrão e o xingar apresentam, portanto, um forte aspecto pragmático: seus sentidos dependem de "padrões de ações linguísticas, funções da linguagem, tipos de inferências, princípios de comunicação, enquadramentos de conhecimento, atitudes e crenças, assim como princípios organizacionais do texto e do discurso". 6 Desta forma, ofende-se, brinca-se ou ridiculariza-se por meio dessas palavras de acordo com o seu uso em determinados contextos e com o ponto de vista dos interlocutores em interação.

A arquibancada de um estádio de futebol brasileiro é um espaço privilegiado para perceber tais dinâmicas. Aqui, torcedores xingam ou proferem palavrões e outros termos de baixo calão constantemente, o que aciona e modela afetos diversos a fim de realizar ações tão diferentes como odiar a equipe adversária, rivalizar jocosamente com torcedores de outros times, indicar a vontade de vitória, indignar-se por uma marcação indevida, etc. Tais dinâmicas eventualmente causam arrepios nos mais polidos e produzem a interpretação de que neste lugar, certas regras sociais se suspendem. No entanto, o que se percebe é um amplo campo no qual preconceitos e opressões sociais se produzem e reproduzem, ou por vezes são tensionados e combatidos.

Diversos trabalhos afirmam que palavrões são termos utilizados para expressar humor, sentimentos e estados de espírito e enfatizam o caráter

\footnotetext{
${ }^{5}$ RANCIÈRE. O desentendimento, p. 49.

${ }^{6}$ BULBLITZ et. al. Preface to the handbook series, p. III.
} 
contextual para a definição da sua ofensividade no ato de xingar. ${ }^{7}$ Dependendo da situação em que são acionados e da relação estabelecida anteriormente entre os interlocutores, estes termos e ações adotam uma feição ofensiva, jocosa ou indignada. Em qualquer uma destas figurações, os autores apontam que o ato de xingar e os palavrões imprimem uma dimensão de intensificação discursiva. No entanto, um aspecto que aparece menos frequentemente em tais estudos é a importância dos aspectos sonoros do xingar e dos palavrões na constituição de seu sentido.

O xingamento "vai tomar no cu", um palavrão de alta ofensividade na língua portuguesa, que remete à homossexualidade e à submissão sexual, assume no contexto futebolístico, povoado de linguagem chula, seu caráter ofensivo máximo apenas quando emitido coletivamente, segundo uma certa prosódia, muito específica, que envolve sua emissão em gritos que aproveitam uma rítmica e melodia próprias à referida expressão. Tal sonoridade é irreprodutível em outras línguas, se pensarmos apenas na tradução das palavras: produzir tal intensificação ofensiva, em linguagem estrangeira, necessitaria outra acentuação, colocação de voz, entonação e variação de alturas. Falado ou gritado com certas características sônicas por torcedores isolados, a expressão pode ser acionada para chamar a atenção de um jogador em campo. Outro exemplo para esta relação entre as sonoridades e os sentidos de xingamentos são os termos "viado" ou "bicha". Nestas condições, o palavrão pode ser acionado de maneira quase automática, como resposta inconsciente a um erro grotesco do atleta em campo em uma dinâmica de afecção mútua, na qual as atitudes corporais do jogador e vocais do público se conectam por meio de um objeto sonoro, "interjeições, vocalizações, sons conversacionais nãoléxicos ou grunhidos marcadores de discurso ou partículas de discurso". 8

\footnotetext{
${ }^{7}$ Sobre o assunto, conferir: CAVAZZA; GUIDETTI, Swearing in political discourse. ZANELLO; GOMES, Xingamentos masculinos. JAY, The utility and ubiquity of taboo words. FÄGERSTEN; DALARNA, A sociolinguistic analysis of swear word offensiveness.

${ }^{8}$ REBER. Affectivity in interaction, p. 25. Destacamos que a autora trabalha com uma definição de afetividade que transcende a de emoção e que se relaciona à exibição culturalmente aprendida de sentimentos, humores, disposições e atitudes associadas a pessoas e/ou situações (REBER. Affectivity in interaction, p. 11), e, portanto, ligeiramente diferente da adotada neste trabalho e que será apresentada mais adiante. No entanto, nos interessa os caráteres de esvaziamento de conteúdo semântico e de resposta semi-inconsciente explorados pela linguística no termo objeto sonoro.
} 
Por outro lado, entoado coletivamente por grande parte da torcida presente na arquibancada segundo outros parâmetros sonoros, é empregado para rechaçar um insulto ou brincadeira dos adversários. Anne Wichmann aponta que tais variações de prosódia no interior de uma mesma língua possuem o efeito pragmático de refletir ou construir relações de poder entre os interlocutores. ${ }^{9} 0$ estudo da prosódia, porém, é dificultado pelo fato de seus conteúdos semântico e para-linguístico serem carregados pelo mesmo canal, o som, o que dificulta separar as duas instâncias. Isto evidencia que "a possibilidade sensata do sentido (ou, se se quiser, a condição transcendental de significação sem a qual não haveria nenhum sentido) recobre-se com a possibilidade ressoante do som". ${ }^{10}$ Desta forma, as sonoridades dos palavrões e xingamentos afetam suas significações em pelo menos duas instâncias. De um lado, realizam um trânsito entre as acepções a que uma mesma palavra ofensiva remete. De outro a própria sensorialidade auditiva empregada na enunciação - seu caráter agressivo proporcionado por uma voz intensa e gutural, por exemplo - exerce um efeito disruptivo sobre os corpos dos interlocutores.

Pierre Sansot conta a história de um juiz de Rugby, identificado como Louis, que arbitrava partidas por prazer. Segundo o árbitro, "não é sempre fácil pronunciar decisões desvantajosas para o time local - estas decisões provocam vaias da multidão", fazendo-o concentrar-se em sua atividade, não ouvindo o "assobio hostil". Tal recalque da escuta não o impedia de "memorizar estes sons, já que as tempestades sônicas a que ele literalmente havia sido surdo durante o jogo, retornavam a seus ouvidos mais tarde". ${ }^{11}$ Este relato evidencia a maneira como, por meio do som, "um poder afetivo flui através do outro: a capacidade de um corpo afetar e ser afetado dá forma e é conformado pelas maneiras nas quais afetam e são afetados por outros corpos". ${ }^{12} 0$ mundo audível viabiliza tal impacto sobre os agentes, pois apresentam uma dupla natureza de força e signo. ${ }^{13}$ Sobretudo em condições de hipersensorialidade, como é o caso do estádio de futebol onde milhares de vozes amplificam uma mesma vibração sonora, a primeira

\footnotetext{
${ }^{9}$ WICHMANN. Prosody and pragmatic effects.

${ }^{10}$ NANCY. À escuta, p. 51.

${ }_{11}$ AUGOYARD; TORGUE. Sonic experience, p. 174.

12 THOMPSON; BIDDLE. Sound, music, affect, p. 9.

13 DAUGHTRY. Thanatosonics.
} 
propriedade toma a frente, dando destaque a aspectos hápticos em detrimento dos seus aspectos cognitivos. Uma pragmática sonora de palavrões e xingamentos, portanto, privilegia uma investigação acerca das intensidades, frequências e espacialidades com que os termos são proferidos e por que interlocutores e em que situações são acionados a fim de perceber o que fazem. A partir deste primeiro esforço de pesquisa é que se torna possível determinar o que significam.

\section{INDIGNAR-SE, ODIAR, BRINCAR E AMAR}

Face a uma marcação injusta de um juiz, uma jogada equivocada da equipe do coração, ou um lance violento de um adversário, a torcida costuma emitir palavrões de maneira coletiva, gritada e com voz agressiva. Frequentemente, após uma série de marcações contrárias, ou a uma única determinação polêmica do árbitro da partida, os torcedores costumam xingar, aos berros e com voz gutural, as palavras "Ei juiz, vai tomar no cu" - seguindo um ritmo e acentuação próprios e marcados, sugeridos pela sonoridade destes termos e que põem em destaque o interlocutor e a palavra "cu". A melodia é reta, sem apresentar variação no campo das alturas, e nenhuma sílaba é alongada. A emissão sonora costuma também rapidamente contagiar todo o estádio, que em questão de segundos a ecoa, evocando uma forte reprovação à atitude da arbitragem. Configura-se, assim, uma multidão que realiza uma ação coletiva de indignar-se, no qual os torcedores pressionam a arbitragem a reverter a decisão tomada - algo muito incomum no decorrer de uma partida de futebol, e inclusive não recomendado pelas regras do esporte - ou a ter mais atenção nas decisões posteriores.

0 mesmo xingamento pode ser acionado quando torcedores se articulam organização esta que pode surgir de maneira espontânea e depois encontrar ressonância em grupos mais institucionalizados - para protestar contra injustiças cometidas pelas entidades organizadoras de campeonatos, ou contra políticos locais. $^{14} 0$ que marca a indignação é o emprego da voz gutural e seu aspecto

\footnotetext{
${ }^{14}$ Um exemplo foi a manifestação da torcida do Coritiba que pediu a saída do Governador Paranaense Beto Richa, após incidente em que a Polícia Militar do estado reprimiu violentamente professores da Rede Pública de Ensino Básico. O fato aconteceu na partida final
} 
coletivo em uma única frase entoada por toda a arquibancada. Este tipo de indignação surge, portanto, como uma agressividade legítima, um sentimento possivelmente comum a qualquer entusiasta de futebol ou amante do esporte, constituindo-se como uma forma de punição às más práticas realizadas na atividade, o que deixa em segundo plano a literalidade do palavrão. Vale ressaltar que protestos e manifestações acontecem também a partir da utilização de termos mais amenos e desprovidos de conotação preconceituosa, ainda que se mantenham as características sônicas do uníssono e da voz gritada e agressiva. Os torcedores alvinegros costumam também indignar-se por más atuações, batendo palmas em um ritmo acelerado, ao final do qual gritam alternadamente "Eu quero é raça" e o nome do jogador cuja atuação é percebida como desanimada. Quando é toda a equipe que atua de maneira apática, a frase "O time todo" é proferida.

Contudo, a sonoridade ofensiva do "Ei..., vai tomar no cu" costuma ser dirigida mais frequentemente a um jogador ou a toda a equipe adversária. Tal xingamento aparece neste formato usualmente quando duas equipes que mantém forte rivalidade se enfrentam, como é o caso do Galo e do Cruzeiro. Tal hostilidade, cuja intensidade parece descabida, visa a intimidar o adversário e prejudicar sua performance em campo. Ela justifica-se por uma construção identitária da equipe, que se dá sobretudo em oposição a este principal rival, ainda que exclua também torcedores de outras equipes, numa espécie de nacionalismo clubístico, onde aqueles que torcem para equipes diferentes comumente convertem-se em inimigos. Assim, torcer para o Galo, amar este clube, significa torcer contra o Cruzeiro, odiar o rival. Por isso, em partidas entre o Galo e Cruzeiro, esta equipe quando entra em campo costuma ser recebida pelos atleticanos com gritos de "Vai tomar no cu".

Aqui, a agressividade da sonoridade do palavrão acionado muitas vezes apresenta uma rispidez que se equivale à dos momentos em que o xingamento se liga à indignação. 0 que marca a diferença entre as duas afecções é não apenas o objeto a que se dirige, mas também o conteúdo sonoro escolhido: o ódio sempre

do Campeonato Paranense, entre Coritiba e Operário de Ponta Grossa, no dia 3 de Maio de 2015. Um relato do ocorrido pode ser encontrado em: Torcidas de Coxa e Operário protestam: "Fora Beto Richa". Gazeta do Povo, Curitiba, 03 mai. 2015. Imagens e áudio do fato disponíveis no Youtube: https://goo.gl/viKFmS. 
utiliza palavrões e xingamentos. 0 odiar costuma manifestar-se como uma tempestade de insultos que se sucedem insistentes, durante um período circunscrito do jogo e que muito frequentemente se mantém restritos a regiões específicas da arquibancada. Esta última característica costuma estar associada a conteúdos semânticos e narrativos extensos, entoados em uma prosódia de difícil compreensão presentes em certas canções utilizadas para esta ação. Tais propriedades dificultam a memorização da peça por aqueles que não pertencem aos grupos de torcedores que a compuseram.

No odiar, percebemos também o caráter sintático de vocativo e de aposto dos palavrões e xingamentos, pois, se de um lado caracterizam os interlocutores, buscam também chamar sua atenção. São atos de fala, portanto, que efetivamente atuam não só sobre seus alvos, enervando-os ou pressionando-os a agir de determinada forma. Eles também impactam aqueles que os emitem, já que podem produzir uma rápida adesão a sua emissão, constituindo grupos de torcedores de forte caráter identitário e excludente.

Esta rivalidade, no entanto, nem sempre aparece sob o signo do ódio violento. Ela também pode apresentar feições amistosas no brincar, ação na qual os palavrões e xingamentos, quando presentes, aparecem com menos intensidade sonora e em vocalizações mais debochadas - o que permite identificar a piada. A jocosidade entre torcedores é frequente e também marca a relação entre amantes de equipes rivais, funcionando como fronteira entre identidades clubísticas muito diferentes. A reciprocidade é também uma das principais características da jocosidade: aquele que faz piada com o adversário se mostra disposto a também ser objeto de brincadeira, quando o momento esportivo das equipes se inverter. Compreender esta dinâmica é essencial para o bom andamento da jocosidade, já que brigas interrompem deste tipo de interação.

Excessos - como brigas ou agressões verbais mais pesadas - quando ocorrem, trazem consequências já na próxima rodada. Como me disse certa vez um informante a esse respeito: “Tem gente que não sabe brincar. Aí a gente não responde, deixa quieto, melhor não se incomodar...".15

\footnotetext{
${ }^{15}$ GASTALDO. As relações jocosas futebolísticas, p. 320.
} 
O brincar pode realizar-se tanto de maneira coletiva - por meio de canções que parodiam aquelas que costumam ser entoadas pela torcida adversária, ou de gritos de guerra dirigidos a atletas rivais específicos - quanto individual, nas interações cotidianas entre torcedores conhecidos. Neste último caso, se dá tanto entre indivíduos ligados à mesma equipe, ou a times adversários. De toda forma, o brincar se dá em colocações de voz jocosas e com intensidades no nível da fala, o que denota o clima amistoso entre os interlocutores. Esta ação também reencena de maneira sonoramente não agressiva os termos da rivalidade entre equipes ao acessar a memória dos confrontos entre os times em questão. 0 som das enunciações é acessado de maneira a enfatizar os momentos passados em que cada clube esteve em melhores condições ou os significados usualmente atribuídos aos amantes de cada time. Entre fãs que compartilham a mesma equipe, o brincar se dá em torno das diferentes formas de torcer e da autenticidade destas práticas, o que delineia disputas em torno de quem é mais torcedor e, portanto, ama mais o clube. Sonoramente, esta jocosidade se dá imitando as práticas torcedoras em questão. 0 brincar também pode ser acionado como forma de início de interação entre torcedores que não se conhecem; os xingamentos e palavrões novamente tomados como brincadeiras que "quebram o gelo" entre quem não tem intimidade.

Finalmente, nota-se uma quarta ação, o amar, que atravessa as outras três. A relação entre os torcedores e o esporte se constrói em torno de fascínios que os atraem à prática, ${ }^{16}$ fixam sua atenção no que acontece em campo e que se manifestam nas formas sonoramente exacerbadas com que o público se manifesta em campo. Diversos tipos de amar, no entanto, estão em jogo nas ações que a torcida realiza por meio do som. Em cada uma delas, vibrações sonoras com características próprias são endereçadas a objetos distintos. Nestas dinâmicas, performances de gênero entram em ação e acionam ou tensionam sensibilidades masculinas, a partir das quais a heteronormatividade a elas inerente se faz presente, cai para um segundo plano, ou apresenta uma possibilidade de subverter-se em processos nos quais as práticas discriminatórias e de resistência à norma se transformam e reconfiguram. Os palavrões e xingamentos são, portanto,

\footnotetext{
${ }^{16}$ GUMBRECHT. Elogio da beleza atlética.
} 
palavras-som que participam ativamente da constituição destes preconceitos e consequentemente de suas qualidades e potências afetivas. As diferentes ações possíveis de se realizar por meio dos palavrões e xingamentos encenam, nas arquibancadas do futebol, estas dinâmicas da heteronormatividade, exibindo-se, portanto, como uma importante instância em que disputas em torno das questões de gênero se dão.

\section{RIVALIDADE E PERFORMANCES MASCULINAS NO FUTEBOL}

A forma como a rivalidade entre times de futebol está organizada em torno da masculinidade, cunhando categorias que se aproximam ou se afastam de ideais que regem sociedades patriarcais torna esta temática um campo fértil para a observação dos processos por meios dos quais os torcedores não só afirmam, mas sobretudo atuam sua macheza. Mais do que ordenar que o adversário, a arbitragem, as instituições que regem o esporte, ou os amigos "tomem no cu", é necessário violentá-los por meio do som. Por isso, focamos a análise de certos casos em que as sonoridades de palavrões, sobretudo aquelas em que a penetração anal é acionada no plano semântico, para perceber como a heteronormatividade é produzida, reproduzida ou combatida no campo de futebol. Lançamos mão sobretudo de exemplos captados em pesquisa de campo em jogos entre o Galo e o Cruzeiro, pois nestas partidas entre rivais locais históricos, percebe-se uma intensificação dos afetos envolvidos na prática esportiva, o que faz aparecer de maneira mais clara tais distinções.

No primeiro tempo do jogo entre as duas equipes válido pela $5^{\mathrm{a}}$ rodada do Campeonato Mineiro de 2014, percebemos como categorias heteronormativas são acionadas para insultar jogadores cruzeirenses em ação de ódio ao adversário. Entre um ataque perigoso do Galo, o atendimento a um jogador cruzeirense, novo ataque perigoso dos atleticanos e contra-golpe celeste interrompido com um carrinho violento do atacante do Cruzeiro Dagoberto no meio campista atleticano Dátolo, passam-se quase três minutos em que as arquibancadas, em todos os seus setores, mas sobretudo próximo à Galoucura, ocupam o espaço sonoro quase unicamente com impropérios dirigidos aos adversários. 0 goleiro cruzeirense 
Fábio escuta da torcida os cantos "Ei Fábio, vai tomar no cu" e "Puta que pariu, a seleção, o Fábio nunca viu". Dagoberto é chamado de homossexual, depois de cometer a falta. Entre os dois lances, a torcida entoa as canções "Cruzeiro Maricones", repetindo indefinidamente estes versos, e "Maria é tudo frouxo", um funk da Torcida Organizada Galoucura que diz:

Dá dó de cruzeirense quando tromba com a gente Bicuda e vários socos só na boca, perde os dentes Sai quebrado e deixando a mulher dele pra trás Peguei a mulher do trouxa e mostrei como TOG faz A mina de repente num descuido ficou louca Viu que TOG é sinistro então pediu beijinho na boca A mina então falou com um sorriso no rosto Dou rolé com Galoucura que os Maria é tudo frouxo Oxo ô oxo, os Maria é tudo frouxo.

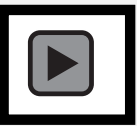

Áudio 2, Galoucura: "Os Maria é tudo frouxo!"

Todos estes insultos e impropérios são entoados com voz gritada, gutural, em grande intensidade, apresentando, portanto, uma grande agressividade, características associadas ao masculino, no contexto do futebol. Quase sempre as sonoridades são puxadas pela Galoucura. Associado ao xingamento, aparecem apelidos jocosos, em que atleticanos chamam cruzeirenses pelo nome próprio feminino Maria. Ressaltamos também o episódio de estupro ou abuso sexual em que a mulher, por medo da organizada, aceita entrar em relação sexual com seus membros. Portanto, aqui a heteronormatividade aparece de maneira mais delineada e premente. A pesquisa também registrou as canções em partidas cujo adversário não era o Cruzeiro. "Os Maria é tudo frouxo", contudo, raramente encontra eco em toda a arquibancada, sobretudo pela letra dos versos entoada em prosódia de difícil compreensão - seu refrão onomatopaico, no entanto, às vezes é repetido por um ou outro torcedor isolado.

A heteronormatividade das organizadas aparece, neste sentido, de maneira totalizante, ao construir um "nós" heterossexual que massacra um "eles" homossexual e, como prêmio pela masculinidade exercida, possui todos os 
indivíduos do sexo feminino, a partir de uma divisão binária calcada na preferência por clubes de futebol. Assim, não basta performar certa macheza. Torna-se necessário distribuir funções às outras formas de expressão de gênero, submetendo - também por meio do som - aquelas diferenças que são aceitas apenas em determinados lugares e destruindo as que apresentam caracteres que desmontam a norma dominante. Nestes momentos, as Organizadas adquirem feição proto-fascista, pois

\footnotetext{
Chamados para o sacrifício para a glória e unidade da nação e do povo sempre possuem um chamado fascista em nossos ouvidos, já que nós os escutamos tão frequentemente, tanto em países dominantes quanto nos subordinados, como o refrão repetido do autoritarismo, totalitarismo e aventuras militaristas. ${ }^{17}$
}

Se estas narrativas nem sempre se realizam em sua literalidade, não é possível também afirmar que se restringem a um plano lúdico e de fantasia. 0 que está em jogo aqui é uma agressão que se dá não só no plano das representações simbólicas mas também no impacto dos sons que estes gritos intensos e violentos produzem nos corpos dos atletas e de outros torcedores que não compactuam com estas dinâmicas. Neste sentido, nota-se como certos jogadores costumam ser alvo mais constante destes insultos de caráter heteronormativo, devido a posição em que atuam em campo situar-se mais próxima da torcida, o que aproxima os palavrões e o ódio da cornetagem - prática de insultar os atletas em campo, seja para atrapalhar a performance atlética dos adversários, seja para corrigir o desempenho do jogador para o qual se torce. Assim, laterais, pontas e goleiros são alvos preferenciais dos xingamentos dos torcedores. A Copa do Mundo de 2014 consolidou uma tendência neste quesito. É comum entre as torcidas mexicanas tentar desconcentrar os goleiros adversários no momento da cobrança de tiro de meta, com o grito "00000000 PUTO!" - o insulto surgindo no momento em que o pé do atleta toca a bola. Nos dois últimos anos, vimos crescer entre os torcedores brasileiros uma apropriação desta sonoridade, trocando o termo Puto, por Bicha, já que ambos designam formas pejorativas de se chamar os homossexuais. No Brasil, o grito é acionado até quando a bola é apenas recuada para o goleiro e por vezes

${ }^{17}$ HARDT; NEGRI. Commonwealth, p. 163. 
surte efeito, já que o jogador chuta a bola diretamente para fora do campo. No caso dos jogos do Galo, o grito se torna mais frequente em partidas contra o Cruzeiro nas quatro disputas entre os arquirrivais que a pesquisa registrou, o grito é entoado praticamente todas as vezes que Fábio chuta a bola. Em partida entre Galo e Cruzeiro, disputada em 13 de Abril de 2014, no Mineirão, pela final do Campeonato Mineiro do mesmo ano, um torcedor atleticano afirmou, depois da execução coletiva do xingamento, que aquele "era o melhor grito de estádio que tinham inventado", demonstrando o apego da torcida à moda latina.

As apropriações de repertórios sonoros realizados pelas Torcidas Organizadas, em que canções dos adversários são parodiadas, utilizando as melodias e trocando as letras de apoio por outras degradantes são outro campo fértil para o ódio dos torcedores. Na partida contra o Cruzeiro relatada no início desta seção, na volta para o segundo tempo, foi possível registrar em todos os setores da arquibancada, e inclusive ao fundo da narração da rádio 98FM, que transmitia a partida, os versos de "Pau no cu do Cruzeiro", paródia de "Vamos, Vamos Cruzeiro". Enquanto os torcedores celestes cantam

\author{
Vamos, vamos Cruzeiro \\ Vamos, vamos a ganhar \\ Vou aonde você for \\ Só pra ver você jogar \\ Com o coração e muito amor \\ Cruzeiro o mais querido do Brasil.
}

A versão atleticana apresenta a seguinte letra:

Pau no cu do Cruzeiro
Bicharada a gritar
Dá o cu aonde for
Só pra ver meu pau entrar
No seu butão não sente dor
Cruzeiro a bicharada do Brasil. ${ }^{18}$

A paródia explicita o preconceito de que o prazer anal é algo anti-natural e, portanto, encerra uma normatividade que se desenvolve a partir da oposição entre dor e prazer: de um lado gostar de ser penetrado em uma relação sexual homossexual aparece como uma acusação de indignidade, de outro a prática é

\footnotetext{
${ }^{18}$ As canções podem ser escutadas no Youtube.
} 
apresentada em analogia à tortura medieval do empalamento. Assim, a capacidade ofensiva do palavrão "Vai tomar no cu" encontra uma de suas bases nesta ambiguidade. 0 termo assume um significado de ultraje e sujeição - remetendo a uma submissão via estupro - quando produz desprazer, e um sentido de devassidão no caso de satisfação sexual - remetendo à homossexualidade, no sexo masculino, ou à prostituição e libertinagem, no feminino. Tal mapa conceitual se liga, portanto, às bases da heteronormatividade, como defende Preciado ao afirmar que "foi necessário fechar o ânus para sublimar o desejo pansexual transformandoo em vínculo de sociabilidade, como foi necessário fechar as terras comuns para sinalizar a propriedade privada" ${ }^{19}$

Nestes termos, a questão se desloca da afirmação do desejo homossexual e por conseguinte de suas políticas de representação, cujas limitações Hardt e Negri $^{20}$ expõem - para a investigação das "técnicas de domesticação, castigo e recompensa que fazem possível a regularidade estrita e calculada do 'desejo heterossexual'", ${ }^{21}$ Delineia-se assim, no caso do futebol, mais um contraste entre o oponente que é submetido a força, como no caso de "Os Maria é tudo frouxo" e aquele que se submete por vontade própria, em "Pau no cu do Cruzeiro". Importante notar também que tanto a versão dos cruzeirenses quanto a dos Atleticanos é entoada com voz gutural, intensa e agressiva, manifestando-se, portanto, como uma performance masculina. Assim, novamente o amor ao time se desenvolve em ódio ao adversário com homofobia.

Destacamos ainda que as organizadas alteram também os repertórios sonoros do próprio clube do coração, de forma a inscrever neles sua marca identitária, disputando a "comunidade imaginada"22 dos torcedores, o que acaba por confundir o clubismo - "modalidade de envolvimento propriamente intensa, ilusória, equivalente ao que os nativos caracterizam como 'torcedor fanático', 'doente', 'cego', etc."23 - e o amor à própria torcida uniformizada. Quando a Galoucura canta "Galo, a razão do meu viver", paródia da canção "Have You ever

\footnotetext{
${ }^{19}$ PRECIADO. Terror anal, p. 136.

${ }^{20}$ HARDT; NEGRI. Commonwealth, p. 332-340.

${ }^{21}$ PRECIADO. Terror anal, p. 161.

${ }^{22}$ ANDERSON. Comunidades imaginadas.

${ }^{23}$ DAMO. Do dom à profissão, p. 66.
} 
Seen the rain" da banda de rock norte americana Creedence, são inseridos, sempre com voz gritada, gutural e agressiva, entre o verso do título e o que leva a alcunha da equipe, a frase "Sou Galoucura até morrer", além de "E dar porrada", após o verso "Nosso lema é vencer". A música, que anteriormente expressava amor ao time manifesta agora amor à torcida. Não é estranho, desta forma, que às vezes irrompam confrontos entre diferentes organizadas da mesma equipe. ${ }^{24}$

Tais observações demostram que o "amor é profundamente ambivalente e suscetível a corrupção". ${ }^{25}$ Percebe-se assim uma estranha forma de patriarcalismo. Nas disputas pela "comunidade imaginada" da torcida, cada organizada delineia o clube como uma pátria distinta. Este nacionalismo - uma máquina cultural ${ }^{26}$ agora $^{2}$ produzindo não nacionalidades, mas apontando para a identidade da equipe ${ }^{27}$ "com sua face moral [...] olha através dos corpos para ver características nacionais, enquanto com sua face militarista, vê o sacrifício dos corpos em batalha, enquanto reveladores do espírito nacional". ${ }^{28}$ Tal desejo de aniquilação da diferença contagia as práticas sonoras que se realizam nos arredores da Torcida Organizada: enquanto a cornetagem em outras regiões das arquibancadas criticam usualmente os jogadores da equipe do coração; próximo à Galoucura, os corneteiros limitam-se a insultar apenas atletas adversários. Esta talvez seja a única manifestação individual realmente aceita neste setor do público.

\footnotetext{
${ }^{24}$ Alguns dos últimos confrontos entre Organizadas em Belo Horizonte ocorreram entre duas torcidas cruzeirenses, a Máfia Azul e a Pavilhão Independente - esta uma dissidência daquela. Um destes episódios ocorreu logo após o término da última partida do Campeonato Brasileiro de 2013, fora do Mineirão, o que cancelou a festa programada pela equipe em comemoração da conquista do titulo nacional daquele ano. Relato sobre o evento em: Briga entre torcidas organizadas do Cruzeiro cancela festa pelo título brasileiro. UOL, São Paulo, 01 dez. 2013. ${ }^{25}$ HARDT; NEGRI. Commonwealth, p. 182.

${ }^{26}$ ALABARCES. Fútbol y patria, p. 26.

${ }^{27}$ Nos últimos cinco anos, tornou-se tradição nos torneios de âmbito nacional ou regional a execução do hino nacional antes do início da partida. A torcida atleticana, neste momento, costuma calar este símbolo da pátria cantando com grande intensidade o Hino do Galo. A esta prática, se articula um sentimento bastante generalizado entre alguns torcedores das equipes do país - os atleticanos inclusive - de desdém com relação à seleção brasileira. Sobre a cantoria do Hino do Galo sob o Hino Nacional, conferir: RIBEIRO, Frederico. Dátolo tem duas dores: ferida na perna e saída do time. Hoje em dia, Belo Horizonte, 29 set. 2015. Sobre o desdém do torcedor dos times nacionais contra a seleção da CBF, PAIVA, Juliano. Torcedor gosta mais do time do que da Seleção. Dom Total, 10 mar. 2014.

${ }_{28}^{28}$ HARDT; NEGRI. Commonwealth, p. 34.
} 


\title{
AMBIGUIDADES HETERONORMATIVAS
}

Note-se, contudo, que nem todas as paródias realizadas entre os rivais apresentam conteúdo preconceituoso e degradante, embora esta seja uma prática corrente entre as torcidas brasileiras. O "Vamos, vamos meu Galo", é um caso de paródia que fica mais no campo das relações jocosas, apropriando-se de "Uma cerveja, por favor". A canção celeste é muito mais agressiva, com seus versos dizendo

\author{
Dá-lhe, dá-lhe Cruzeiro \\ Dá-lhe, dá-lhe Cruzeiro \\ Uma cerveja por favor \\ Eu sou Cruzeiro até morrer \\ E para sempre eu vou te amar \\ E o galinheiro eu vou queimar.
}

Do que a atleticana, composta em comemoração à conquista da Copa Libertadores da América, em 2013, e que diz:

\author{
Vamos, vamos meu Galo \\ Vamos, vamos meu Galo \\ E pra Marrocos, eu quem vou \\ 0 mundial eu vou vencer \\ E as marias eu vou zuar \\ Quando chegar em BH.
}

Estas canções usualmente alcançam o uníssono nas arquibancadas e são entoadas com voz intensa, contudo são mais cantadas do que gritadas e o gutural não é utilizado. Nota-se, também, que os adversários são tratados por meio de termos que lhes negam masculinidade: o nome próprio feminino Maria é atribuído aos cruzeirenses, o termo galinheiro, em alusão ao apelido de Frangas com o qual os atleticanos são chamados por seu rival. Aqui, percebe-se de que forma as performances e sensibilidades masculinas muitas vezes flertam com a heteronormatividade, em um mecanismo sonoro ambíguo que "reproduz seus mecanismos de arbitrariedade (...); e nesta reprodução os exibe". ${ }^{29}$

Outros casos de brincadeira expõem dinâmicas ambíguas semelhantes. A canção "Maria, eu sei que você treme" é um deles. Trata-se de uma apropriação da

\footnotetext{
${ }^{29}$ ALABARCES et. al. Aguante y repression, p. 219.
} 
torcida atleticana de versos cantados por torcedores argentinos, que por sua vez parodiaram a composição "Bad moon rising", da banda de rock americana Creedence. ${ }^{30}$ A composição também apareceu como febre entre as torcidas brasileiras, após a Copa do Mundo de 2014, quando os platinos compuseram uma versão em alusão à seleção brasileira, contando com adaptações de torcidas de diversas equipes do Brasil. Em sua figuração atleticana, os torcedores relembram momentos de glória da equipe, dando especial ênfase àqueles que aconteceram contra o Cruzeiro, cantando:
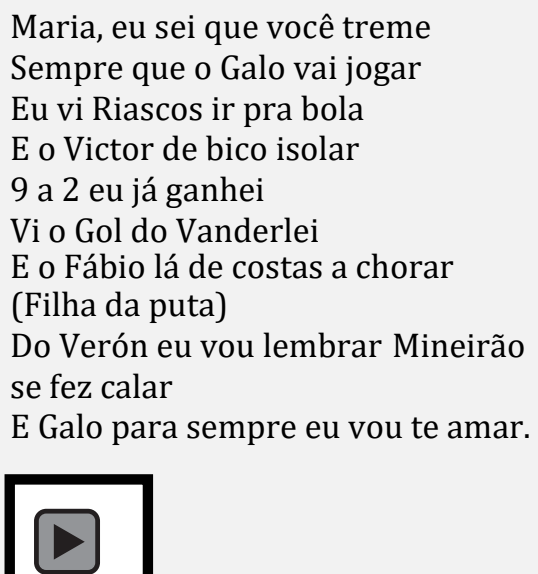

Áudio 3, Galoucura: "Maria, eu sei que você treme"

A canção é entoada em tom debochado, antes das partidas, ou quando a vitória atleticana já é dada como certa, frequentemente encontrando adesão de todo o estádio, momento no qual atinge grande intensidade sonora. Também é bastante comum que a torcida deixe o estádio cantando estes versos depois de uma vitória. A composição, cuja autoria não se deve às organizadas, mas a torcedores independentes que a espalharam pelas redes sociais, foi entoada diversas vezes durante a partida contra o Cruzeiro pela final da Copa do Brasil de 2014, sobretudo antes da partida, depois dos gols atleticanos e nos períodos finais de cada tempo - além é claro da saída dos torcedores após o jogo. Ela encerra uma

\footnotetext{
${ }^{30}$ Para uma narrativa da história que leva a canção da banda norte-americana até os estádios de futebol, conferir ALABARCES. Fútbol, música y narcisismo.
} 
forte ligação com o título nacional conquistado sobre os arquirrivais atleticanos naquela partida. ${ }^{31}$

Ainda que predominantemente jocosa e de forte tom memorialista, a heteronormatividade na qual se baseia - a partir do nome Maria e da covardia atribuídos ao adversário - abre espaço para ocasionais manifestações de ódio ao Cruzeiro em sua performance. Frequentemente, quando a canção cita o goleiro cruzeirense Fábio, certos torcedores mais exaltados gritam o xingamento "Filha da Puta", sempre com intensidade mais elevada do que aquela com que se canta o restante da canção, e com um tom de voz bastante gutural, agressivo e ríspido. 0 fato mostra como a torcida oscila rapidamente entre afetos diferentes de amor à equipe e à torcida, delimitando também fronteiras bastante tênues entre o ódio e a jocosidade, realizando deslocamentos sensíveis e efêmeros entre a ofensa e a brincadeira. Assim, no momento em que o insulto é performado da maneira descrita, os elementos que reencenavam a memória afetiva de um clube são silenciados em favor de uma sonoridade que

nomeia a persistência do machismo, a discriminação de toda alteridade basicamente uma profunda homofobia. Se há rebeldia, esta insiste no velho tópico da reprodução da dominação no interior dos dominados, legível também na recorrência racista. ${ }^{32}$

\section{CONSIDERAÇõES FINAIS}

Neste emprego dos xingamentos, percebe-se uma intenção dos torcedores em subjugar, por meio do som, os adversários ou instituições que regulam a prática esportiva, no específico, ou a vida social, no geral. Assim, uma questão se coloca: de que maneira a torcida busca submeter o oponente? Por piadas relacionadas à performance esportiva? Por violência física? Por violência simbólica que ameaça

${ }^{31}$ Este fato fez com que alguns torcedores propusessem a mudança de alguns versos. "Do Verón Eu vou lembrar" seria substituído por "Do Tardelli eu vou lembrar" em menção ao gol da vitória do segundo jogo da final, disputada no Mineirão, marcado por este atleta. "Esperando a Quarta Feira do Goulart" tomou o lugar de "E galo para sempre eu vou te amar" em uma brincadeira com o atacante celeste Ricardo Goulart que na rodada do Campeonato Brasileiro realizada no final de semana entre as duas partidas finais da Copa do Brasil, em que os cruzeirenses conquistaram o título nacional de 2014, respondeu de maneira muito otimista à pergunta de um jornalista sobre o jogo que se realizaria três dias depois: "Quarta Feira tem mais".

${ }^{32}$ ALABARCES et. al. Aguante y repression, p. 224. 
uma violação sexual? Compreender a processualidade destas disputas - manifestas em performances de gênero - no campo do esporte, torna-se uma chave para investigar como se dão tais dinâmicas na sociedade como um todo, na medida em que os preconceitos, lutas e negociações presentes no estádio são os mesmos que atravessam os demais campos sociais.

Neste sentido, a heteronormatividade é acessada de diferentes maneiras nas arquibancadas, de forma a tensionar, reinventar ou re-encenar preconceitos de gênero neste espaço a partir de modulações acústicas das sonoridades de palavrões. Tais dinâmicas apresentam uma grande ambiguidade, e a torcida caminha sempre numa linha tênue entre uma agressividade legítima contra abusos sofridos e uma reprodução violenta de uma masculinidade normal, não desviante. No caso do "Ei..., vai tomar no cu" gutural, indignado e entoado em uníssono em decorrência de uma pretensa injustiça sofrida pelo time pelo qual se torce encontramos um momento em que a base homofóbica do xingamento vai a segundo plano, em relação a outras questões em jogo na ocasião. Aqui, a multidão presente responde a uma situação de ultraje - e, portanto, submissão - por uma ação ilegítima de um juiz, instituição esportiva ou da sociedade, ou de um ente político, e por isso busca submeter seu carrasco a partir dos próprios termos em que uma dimensão desta opressão se dá. Na medida em que os torcedores estão imersos em uma cultura misógina, a torcida devolve seu sofrimento com os recursos que tem: metaforicamente "estuprado" por uma injustiça, ele, indignado, "sodomiza" sonoramente seu algoz. Trata-se, portanto, de uma agressividade legítima, constituindo-se como uma forma de punição às más práticas realizadas na atividade.

No odiar, ao contrário da indignação, a heteronormatividade aparece de maneira mais delineada e premente, acionando uma construção identitária da equipe, que se dá sobretudo em oposição ao principal rival, ainda que exclua também torcedores de outras equipes, numa espécie de nacionalismo clubístico. Nesta dinâmica, reproduz-se lógicas heteronormativas nas quais desenha-se uma outra forma de submissão onde aquele que é submetido extrai prazer e gosta de sua condição subalterna, como mostra a canção "Pau no cu do Cruzeiro". Fica estabelecida assim uma tríplice fronteira entre o macho ativo, o forçado à passividade e o homossexual sempre passivo, reduzido ainda à condição de 
covardia e de dominado que uma cultura misógina atribui ao feminino. Assim, ética sexual e coragem - o "aguante" argentino ${ }^{33}$ - se sobrepõem.

Já o brincar manifesta-se, por meio de vocalizações bem humoradas, a jocosidade entre torcedores na qual a relação entre amantes de equipes rivais é marcada por fronteiras entre identidades clubísticas muito diferentes desenhadas em sensibilidades masculinas que muitas vezes flertam com a heteronormatividade. Tal mecanismo sonoro ambíguo de fabulação expõe a lógica que rege a normalidade performativa vigente na sociedade, ao mesmo tempo reproduzindo-a e mostrando suas contradições e violências.

Espanta-me o excesso de ódio e agressividade voltado a motivos banais, como a simples presença do adversário. Se por um lado os estudos sobre futebol e hooliganismo apontam que a prática esportiva visa a produção de um estado de intensificação da excitação; ${ }^{34}$ por outro a formação da sensibilidade e afetividade masculinas sob uma lógica heteronormativa aparece como uma importante força na homofobia destes excessos. As diferentes manipulações acústicas de uma mesma sonoridade ofensiva fazem aparecer, enfim, o caráter de veneno-remédio do futebol, como Wisnik aponta:

O quadro traçado indica o lugar único que o futebol acabou por ocupar no mundo contemporâneo. É um lugar amplamente exposto à violência entre iguais, à Guerra horizontal de classes, ao dilaceramento social e à anomia, que encontram nele um ponto de descarga. Exposto igualmente a todas as manobras da publicidade capitalista, é ainda assim, o lugar onde se encontra algo que falta ao 'cotidiano capitalista', (...) ou algo que não se encontra facilmente no mundo: um código simbólico reconhecível, capaz de expressar e atravessar as diferenças culturais, a postulação e a superação da concorrência na forma de um jogo-rito, a quadratura do circo, mesmo no limite da sua inviabilização. ${ }^{35}$

É neste sentido que o recente surgimento de grupos de torcedores queer ${ }^{36} \mathrm{e}$ de torcidas de esquerda e antifascistas ${ }^{37}$ no Brasil poderia apontar algumas formas

\footnotetext{
${ }^{33}$ ALABARCES. Héroes, machos y patriotas, p. 160.

34 DUNNING; MURPHY; WILLIAMS. The roots of football hooliganism.

${ }^{35}$ WISNIK. Veneno remédio, p. 429.

36 MENDONÇA Renata. Ambiente 'hostil e opressor' afasta torcidas gays dos estádios. BBC Brasil, São Paulo, 19 set. 2014.

37 Entre os atleticanos, destacamos a Galo Marx, a Galo Antifa e a Galo Ultra Antifas. Informações sobre os grupos podem ser encontradas em suas páginas no Facebook.
} 
políticas de utilização de palavrões e xingamentos heteronormativos, manipulados em sua sonoridade de forma a fazer do futebol "instrumento de crítica, em vez de alvo".38 Galo Queer, Gaivotas Fiéis e Bambi Tricolor são nomes que partem da adoção de termos ofensivos pelos grupos ofendidos por tais insultos, de forma a delinear uma inversão de valores que traz a potência de questionar normas constituídas, na medida em que

recompõe[m] as relações entre os modos do fazer, os modos do ser e os modos do dizer que definem a organização sensível da comunidade, as relações entre os espaços onde se faz tal coisa e aqueles onde se faz outra, as capacidades ligadas a esse fazer e as que são requeridas para outro ${ }^{39}$

Contudo, tais grupos, sobretudo por medo de repressão física dos demais torcedores, não se fazem presentes nos estádios de maneira visível ou audível. Talvez, se fossem ouvidos nas arquibancadas em sonoridades zombeteiras ou orgulhosas de suas "afrontas" à heteronormatividade, o foco da ferocidade da indignação torcedora poderia mudar de alvo, sobretudo quando se considera que o futebol mantém relações econômicas e sociais tão corruptas quanto as que apresentam contemporaneamente - sua principal entidade organizadora se vê envolvida em escândalos de corrupção ao redor do mundo.

Importante notar, neste sentido, que estas relações corruptas se apresentam não só no âmbito das instituições que organizam, administram e exploram economicamente a prática do futebol, mas também as relações entre torcidas organizadas entre si, entre estas e outros torcedores e as próprias entidades estruturantes do esporte. Por exemplo, são várias - e geralmente inconclusivas - as acusações de ingerência e abusos das Torcidas Organizadas, que utilizam sua potência agregadora para criar ambientes desfavoráveis para gestões que se recusam a garantir-lhes entrada gratuita nos jogos, ou venda irregular de ingressos que foram cedidos previamente a estes grupos organizados. Tais fatos apontam que a violência entre organizadas do mesmo time pode possuir também um significado de confrontos em torno destes canais extra-oficiais de recursos econômicos e que

\footnotetext{
${ }^{38}$ GUMBRECHT. Elogio da beleza atlética, p. 30.

${ }^{39}$ RANCIÈRE. O desentendimento, p. 52.
} 
envolvem também uma mais valia material, contrariando a ideia de que o torcer neste caso o torcer organizado - envolve apenas um excesso simbólico. ${ }^{40}$

Explicitar-se-ia, portanto, que algumas Organizadas - talvez sobretudo as maiores de cada equipe - mais do que visar “o negócio futebolístico e, em meio a tanta corrupção, se limitam a reclamar a sua parte, que nem sequer é a mais importante" ${ }^{41}$ possuem alguma parcela de responsabilidade nestas dinâmicas de apropriação indébita das afetividades do conjunto de torcedores - organizados ou não - de um clube. ${ }^{42}$ No entanto, são escassos os estudos sobre as relações entre diferentes grupos de torcedores, organizados ou não. Ainda assim, a pesquisa de campo sobre as sonoridades do estádio realizada para a produção deste artigo - e que representa ainda um esforço inicial neste sentido - delineia a hipótese de que a atuação heteronormativa de grupos como a Galoucura seria uma das instâncias do esporte que assumem, ainda que em pequena escala, feições de polícia: "processos pelos quais se operam a agregação e o consentimento das coletividades, a organização dos poderes, a distribuição dos lugares e funções e os sistemas de legitimação dessa distribuição". ${ }^{43} 0$ silêncio de grupos de torcedores queer e antifascistas nos estádios evidenciaria que as disputas nas arquibancadas em torno das formas de torcer esconderiam interesses de ordem material. Performances masculinas como patrimonialismo, enfim.

\section{REFERÊNCIAS}

ALABARCES, Pablo et al. Aguante y repression. Futbol, violencia y politica en la Argentina. In: ALABARCES, Pablo. Peligro de gol. Estudios sobre deporte y sociedad en América Latina. Buenos Aires: CLACSO, 2000.

\footnotetext{
${ }^{40}$ ALABARCES et. al. Aguante y repression, p. 216.

${ }^{41}$ ALABARCES. Héroes, machos y patriotas, p. 174.

42 Gustavo César Arêas de Souza (Em nome da Excitação) realizou uma etnografia sobre as relações entre a torcida do Fluminense Young Flu e a diretoria deste clube. Este foi o único trabalho acadêmico encontrado acerca do tema. Sobre a pressão da Galoucura sobre a diretoria atleticana em torno da distribuição de ingressos gratuitos para a torcida, conferir: Galoucura e presidente do Atlético-MG estão em confronto. UOL, São Paulo, 07 jul. 2007. Sobre a venda irregular de ingressos destinados à mesma organizada por seus membros, conferir: LACERDA, Bernardo e FERNANDES, Thiago. Organizadas revendem ingressos da final distribuídos pelo Atlético-MG. UOL, São Paulo, 26 nov. 2014.

${ }^{43}$ RANCIÈRE. O desentendimento, p. 41.
} 
ALABARCES, Pablo. Fútbol y patria. Buenos Aires: Prometeo Livros, 2007.

ALABARCES, Pablo. Héroes, machos y patriotas: el fútbol entre la violência y los médios. Buenos Aires: Aguilar, 2014.

ALABARCES, Pablo. Fútbol, música y narcisismo: algunas conjeturas sobre "Brasil, decime qué se siente". El oído pensante, v. 3, n. 1, p. 1-19, 2015.

ANDERSON, Benedict. Comunidades imaginadas: reflexões sobre a origem e a expansão do nacionalismo. Lisboa: Edições 70, 2005.

ATLÉTICO ANTIFASCISTA, Facebook. Disponível em: https://goo.gl/5KxZt3. Acesso em: 22 out 2016.

AUGOYARD, Jean François; TORGUE, Henry. Sonic experience: a guide to everyday sounds. London: McGill-Queen's University Press, 2005.

BBC BRASIL, São Paulo, 19 set. 2014. Disponível em: https://goo.gl/UURrzP. Acesso em: 29 jul. 2015.

BULBLITZ, Wolfram, et. al. Preface to the handbook series. In: ANDERSEN, Gisle; AIJMER, Karin. Pragmatics of society - Handbook of pragmatics, 5. Berlin: Walter de Gruyter GmbH \& Co., 2011.

CAVAZZA, Nicoletta; GUIDETTI, Margarida. Swearing in political discourse: why vulgarity works. Journal of Language and Social Psicology, v. 33, n. 5, p. 537-547, 2014.

DAMO, Arley Sander. Do dom à profissão: Uma etnografia do futebol de espetáculo a partir da formação de jogadores no Brasil e na França. 2005. 435 p. Tese (Doutorado em Antropologia Social) - Programa de Pós-graduação em Antropologia Social, Universidade Federal do Rio Grande do Sul, Porto Alegre, 2005.

DAUGHTRY, Martin. Thanatosonics: ontologies of acoustic violence. Social Text, v. 119, 32, n. 2, p. 25-51, 2014.

DOM TOTAL, 10 mar. 2014. Disponível em: https://goo.gl/sD926t. Acesso em: 20 ago. 2017.

DUNNING, Eric; MURPHY, Patrick; WILLIAMS, John. The roots of football hooliganism. Nova York: Routledge, 2014.

FÄGERSTEN, Kristy; DALARNA Högskolan. A sociolinguistic analysis of swear word offensiveness. Saarland Working papers in linguistics, v. 1, p. 14-37, 2007.

GALO ANTIFA, Facebook. Disponível em < https://goo.gl/2qyVnd>. Acesso em: 22 out. 2016.

GALO MARX, Facebook. Disponível em: https://www.facebook.com/GaloMarx/. Acesso em: 22 out 2016.

GASTALDO, Édison. As relações jocosas futebolísticas. Futebol, sociabilidade e conflito no Brasil. Mana, v. 16, n. 2, p. 311-325, 2010.

GAZETA DO POVO, Curitiba, 03 mai. 2015. Disponível em: https://goo.gl/JeBptA. Acesso em: 29 jul. 2017. 
GUMBRECHT, Hans Ulrich. Elogio da beleza atlética. São Paulo: Companhia das Letras, 2007.

GUMBRECHT, Hans Ulrich. Is there anything wrong with violence? About the beauty of rugby and American Footbal. Philia\&Filia, v. 1, n. 2, jul.-dez., p. 67-72, 2010.

HARDT, Michael; NEGRI, Antônio. Commomnwealth. Cambridge: The Belknap Press of Havard University Press, 2009.

HOJE EM DIA, Belo Horizonte, 29 set. 2015. Disponível em: https://goo.gl/YjVRRh. Acesso em: 20 ago. 2017.

JAY, Timothy. The utility and ubiquity of taboo words. Perspectives on Psicological Sciences, v. 4, n. 2, p. 153-161, 2009.

NANCY, Jean-Luc. À escuta. Belo Horizonte: Edições Chão de Feira, 2014.

PRECIADO, Beatriz. Terror anal: apuntes sobre los primeros días de la revolución sexual. In: HOCQUENGHEM, Guy. In: El deseo homosexual. Barcelona: Melusina, 2009, p. 135-174.

RANCIÈRE, Jacques. O desentendimento. Política e filosofia. São Paulo: Ed. 34, 1996.

REBER, Elizabeth. Affectivity in interaction: sound objects in english. Philadelphia: John Benjamins B.V, 2012.

SOUZA, Gustavo César Arêas de. Em nome da excitação: Uma etnografia da relação política entre torcedores organizados e dirigentes de futebol. Dissertação de mestrado apresentada no Programa de Pós-Graduação em Ciências Sociais da Universidade Federal Rural do Rio de Janeiro.

THOMPSON, Marie; BIDDLE, lan (orgs.). Sound, music, affect: theorizing sonic experience. Nova York: Bloomsbury, 2013.

UOL, São Paulo, 26 nov. 2014. Disponível em: https://goo.gl/LBtxmL. Acesso em: 18 jul. 2017.

UOL, São Paulo, 01 dez. 2013. Disponível em: https://goo.gl/GS5q7j. Acesso em 29 jul. 2017.

UOL, São Paulo, 07 jul. 2007. Disponível em: https://goo.gl/YNbkFD. Acesso em: 18 jul. 2017.

WICHMANN, Anne. Prosody and pragmatic effects. In: ANDERSEN, Gisle; AlJMER, Karin. Pragmatics of society - Handbook of pragmatics, 5. Berlin: Walter de Gruyter GmbH \& Co., 2011

WISNIK, José Miguel. Veneno remédio: o futebol no Brasil. São Paulo: Companhia das Letras, 2008.

ZANELLO, Valeska; GOMES, Tatiana. Xingamentos masculinos: a falácia da virilidade e da produtividade. Caderno Espaço Feminino, v, 23, n. 1/2, p. 265280, 2010. 